Western University

Scholarship@Western

Law Publications

Law School

1993

\title{
A Study of the Effect of Controlling the Flow of Information through Imposition of Statutes
}

Margaret Ann Wilkinson

Western University, mawilk@uwo.ca

Follow this and additional works at: https://ir.lib.uwo.ca/lawpub

Part of the Law Commons

Citation of this paper:

Wilkinson, Margaret Ann, "A Study of the Effect of Controlling the Flow of Information through Imposition of Statutes" (1993). Law Publications. 81.

https://ir.lib.uwo.ca/lawpub/81 


\section{A Study of the Effect of Controlling \\ Flow of Information \\ Through Imposition of Statutes \\ by \\ Dr. Margaret Ann Wilkinson ${ }^{1}$}

\section{Introduction:}

Many scholars and policy-makers are concerned about formulating government responses to the changing directions of Canadian society as we become an "information society". There is concern about Canada's ability to cope with changing global economic conditions as we enter the "information age". There are calls for a national information policy. However, the way to achieve an effective policy to help Canadians cope with the transition to the information age is by no means clear. ${ }^{2}$ A large part of the problem stems from our lack of precise knowledge about the changes such a policy would be intended to address. These difficulties are compounded because we are not clear about the central phenomenon of the change: information.

As we struggle to address changing conditions, we cannot judge the effectiveness of our attempts at policy implementation unless we know where to look to measure the impact of our initiatives. Measurement implies that we have an understanding of the phenomenon of information that will permit effective empirical analysis.

Traditional views of the role of government often concentrate upon questions of the rights of the individual as contrasted with the governing power of the state. Indeed, two central aspects of a government's information policy are: (1) the extent to which information held by government about private individuals is protected; and (2) the extent to which access to information held by government will be given to those outside government. ${ }^{3}$

${ }^{1}$ Assistant Professor, Faculty of Law and Graduate School of Library and Information Science, University of Western Ontario This paper is drawn from the author's dissertation entitled "Impact of the Ontario Freedom of Information and Protection of Privacy Act, 1987 upon Affected Organizations" Ph.D. dissertation, University of Western Ontario, 1992). The author was supported in that work through scholarships from both the Ontario government and the Social Science and Humanities Research Council of Canada. This paper has been prepared with the assistance of Catherine Eckenswiller, a research assistant provided through a grant from the Law Foundation of Ontario.

${ }^{2}$ See "Summary of Working Group Discussions" in the Summary Report of the National Summit on Information Policy 1992 (Ottawa: Canadian Library Association, 1993) at 11-20.

3 Traditionally, there was no particular protection accorded to personal information which government had collected. Similarly, individuals outside government have traditionally had no right to access government information, although government could choose to make information available. Indeed, in the province of Alberta and in the Northwest Territories these traditional positions are still the law. The extent of the personal data protection and access to government information which has been made available in other parts of Canada through legislation varies from jurisdiction to jurisdiction. For further discussion of the legal aspects of information 
The Ontario government has recently passed two laws and created a single administrative framework which have radically altered information law in Ontario in these two areas (at least theoretically). The first of these statutes, the Freedom of Information and Protection of Privacy Act, 1987, 4 was the subject of the research from which this paper is drawn. ${ }^{5}$ The policy intent of the Ontario legislature in creating this information legislation was given expression in the first section of the statute itself: 6

(a) to provide a right of access to information under the control of institutions in accordance with the principles that,

(i) information should be available to the public,

(ii) necessary exemptions from the right of access should be limited and specific, and

(iii) decisions on the disclosure of government information should be reviewed independently of government; and

(b) to protect the privacy of individuals with respect to personal information about themselves held by institutions and to provide individuals with a right of access to that information.

Although framed in terms of information, the Act does not give a definition of "information". Indeed, this research used a model of the information process which does not require a definitive definition of the concept of information. Rather the research design builds upon the one aspect of information which is common to all the definitions of information proffered in the literature: ${ }^{7}$ information characteristically flows.

Flow has two components: direction and volume. Our gaps in understanding would appear to prevent accurate analysis, as yet, of the volume of flow of information. However, the direction of the flow of information is more amenable to accurate observation, and it is on this aspect of the empirical measurement of the behaviour of information that this research focussed.

Certain patterns in the direction of the flow of information in society have been revealed in the area of research focussed on the information acquisition patterns of individuals in various segments of society (as for example, the large studies in which Brenda Dervin has been involved). ${ }^{8}$ Some

policy see Barry Cleaver, Margaret Ann Wilkinson, et al, Handbook Exploring the Legal Context of Information Policy in Canada (London: Faxon Canada, 1992).

4 R.S.O. 1990, c.F.31. Hereinafter referred to as "the Act". It came into effect January 1, 1988 (see s.72). It was originally supposed to come into force with respect to municipal institutions three years later (see s.2(3) in the original enactment) but, instead, the municipal lobby persuaded government that its own unique enactment was necessary.

5 This statute applies to the provincial government and its agencies. The second Ontario statute is the Municipal Freedom of Information and Protection of Privacy Act, 1989, R.S.O. 1990 , c.M-56. This statute has applied to municipal institutions since January 1, 1991, see 5.52(1).

6 See s. 1 of the Act.

7 With the exception of those definitions which merely define information by analogy to another phenomenon, such as real or personal property.

8 See Brenda Dervin, et al., The Development of Strategies for Dealing with Information 
influences on the direction of the flow of information have also been explored in earlier studies. As early as the late sixties, Victor Rosenberg found that both industrial and government personnel go to the easiest and most convenient sources for information rather than to the source having the most information. ${ }^{9}$ In the same vein, Mary Culnan has shown more recently that people choose between library systems, an online information system, and interpersonal sources for information based on perceived ease of use (which comprises both accessibility and familiarity). 10

These studies were focused on the individual, and did not attempt to reach conclusions about the organizations in which these individuals found themselves. But Florence Heffron writes that "[o]rganizations are the primary means by which public policy is implemented." 11 These organizations are undergoing profound change to respond to the new economy. Donald Lamberton concluded that the "literature of economics has shown a sharpening focus on the role of the organization." 12 Government activity or inactivity in assisting organizations to make the transition to the information-based economy will be crucial to our national future to the futures of individuals and governments in our society.

The INISS study, done in the late seventies by T. D. Wilson and others, was a major study of information flow in an organization: social workers in one particular government department in England. ${ }^{13}$ There is another piece of research explored the reasons for knowledge disavowal ${ }^{14}$ in large American industrial goods manufacturing organizations. 15

Another area of research concerned with information flow is the work which has been done in the area of the distinction between formal and informal channels of communication. ${ }^{16}$ There are studies distinguishing between these

Needs of Urban Residents (Bethesda, Md.: ERIC Document Reproduction Service ED 125-640 (Phase 1), ED 136-791 (Phase 2), and ED 148-389 (Phase 3)).

9 Victor Rosenberg, "Factors Affecting the Preferences of Industrial Personnel for Information Gathering Methods," Information Storage and Retrieval 3 (1967): 119-27.

10 Mary J. Culnan, "The Dimensions of Perceived Accessibility to Information: Implications for the Delivery of Information Systems and Services," Journal of the American Society for Information Science 36 (1985): 302-308.

11 Florence Heffron, Organization Theory and Public Organizations: The Political Connection (Englewood Cliffs, N.J.: Prentice Hall, 1989), p. ix.

12 Donald M. Lamberton, "The Economics of Information and Organization," ARIST 19 (1984): 3-30 at 22.

13 See, among other reports of the study, T. D. Wilson, "The Cognitive Approach to Information-Seeking Behaviour and Information Use," Social Science Information Studies 4 (1984): 197-204; and T. D. Wilson and D.R. Streatfield, "Information Needs in Local Authority Social Services Departments: an Interim Report on Project INISS," Journal of Documentation 33 (1977): 277-93.

${ }^{14}$ The avoidance of available information by middle managers in order to protect the status quo.

15 Rohit Deshpande and Ajay K. Kohli, "Knowledge Disavowal: Structural Determinants of Information-Processing Breakdown in Organizations," Knowledge: Creation, Diffusion, Utilization 11 (1989): 155-69. 
two types of channels in the context of an organization. One such study indicates that the actual operation of an organization may rely on informal

communications channels to a large extent, rather than on formal ones. ${ }^{17}$ The legislation with which the present research is concerned does not specifically confine itself to either formal or informal communication. The legislation is framed in terms of controlling the flow of information contained in "records", that is, information physically preserved in any kind of medium. ${ }^{18}$ This does not necessarily mean that information must flow in formal channels to be affected by the Act, although public or official channels tend to utilize records. ${ }^{19}$

This research was concerned, then, to investigate the effect of active government policy implementation to alter the flow of information in society. Such an intervention had occurred in Ontario in 1987. The stated intention of the legislative enactment was to create absolute rights in individuals to insist upon a flow of information (other than personal data) out of Ontario provincial government organizations and to absolutely dam any flow of personal information out of those same organizations (except to the individual subjects of the personal data).

Although the Ontario legislation in its opening section reflects a traditional preoccupation with the rights of the individual as contrasted with the governing power of the state, the architecture of this new administrative law area basically places the onus for the implementation of this change in Ontario's information climate in the hands of the affected organizations. Therefore, this exploratory research focussed on the role of the organizations charged with compliance with the statute. Six of the nine hypotheses tested in the research

\footnotetext{
16 Formal channels are those which are externally validated by being made public or official in some way. An instance of the use of a formal channel is publication of press releases by an employee as part of his or her duties. Another type of formal communication is written official correspondence. All written communications are not formal, although written communication tends to demonstrate the existence of a formal channel more often than does oral. On the other hand, formal channels do include mandated oral communications. Informal communications are all forms of communication which are not formal. Telephone conversations with a co-worker who provides information as a colleague and friend rather than because officially required to do so are an example of informal communication. A memorandum sent by a colleague in another organization as a personal initiative is another example. See Judith Weedman, "Informal and Formal Channels in Boundary-Spanning Communication," Journal of the American Association for Information Science 43(3) (April 1992): 257-67 at 257.

17 William Paisley, "Information and Work," Progress in Communication Sciences 2 (1980): 113-65.

18 There is an exception to this statement in that acquisition by affected organizations of personal information orally is also controlled under the Act.

19 Indeed, W.D.Garvey and B.C.Griffith include the condition that the information carried remain in 'permanent' storage to the requirement that it be public in defining formal channels. By contrast, informal channels were said to carry information to restricted audiences which was then relatively temporarily stored. See "Informal channels of communication in the behavioural sciences: their relevance in the structuring of formal or bibliographic communication," in The Foundations of Access to Knowledge, ed. E.B. Montgomery (Syracuse University, 1968): $129-46$ at 131.
} 
dealt with questions contrasting and comparing the implementation and adoption of the legislation in various types of affected organizations. One dealt with issues of organization structure. Those seven aspects of the research will be reported elsewhere. The remaining two were concerned with the issue of information flow in the organization and are therefore reported upon in this paper:
-That changes had occurred in directions of flow of information in the subject organizations as a result of this legislation.
-That the legislation had affected formal information channels in the organizations to a greater degree than informal channels.

\section{Methodology:}

The study was conducted in eight selected Ontario government organizations: four ministries and four crown corporations. Data were obtained from four different sources in each organization. ${ }^{20}$ All data were gathered between fall 1990 and February 1992.

The first source of data was an interview conducted with the Freedom of Information and Privacy Coordinator in each organization. ${ }^{21}$ The data gathered during this interview was largely qualitative, rather than quantitative.

A second source of evidence, written documentation bearing upon the issues, was requested during the course of each interview with the Coordinator. This evidence included such material as the organization's reports to the Information and Privacy Commissioner, ${ }^{22}$ policy manuals, training materials, organization charts (both before and after the implementation of the Act), and job descriptions. Data from internal documentary sources were obtained from seven of the eight organizations.

Next, a twenty-two question survey was distributed to employees. Two of the smaller organizations surveyed were not sampled. Response rates of 42 and $44 \%$ were obtained. ${ }^{23}$ In the other four organizations involved in the survey portion of the research, a stratified random sample of employees at different levels in the organization hierarchy was used. Six hundred

20 Several of the organizations did not provide data from all four sources, as noted below. Some details of the methodology are not germane to the issues being dealt with in this paper and have therefore been omitted from this account.

21 This position was created in each organization as a result of the imposition of the statute on these organizations, although the position is not, in fact, mandated by the legislation itself.

22 The independent officer created under the statute to make decisions on complaints brought by individuals using the Act.

23 Because of the confidentiality arrangements made with the subject organizations, the size of these two cannot be given. 
questionnaires were distributed amongst the four. Here response rates were $47 \%, 60 \%, 60 \%$ and $65 \%$.

The final aspect of data gathering was a forty-five minute interview with the head of each organization or his or her delegate. ${ }^{24}$

\section{Findings:}

Only $12 \%$ of all respondents to the questionnaire made comments which indicated that they had made changes in acquisition or dissemination of information; in other words, in the flow of information in their organization.

Only a very few comments could be classified as affecting acquisition changes (five in all), and these are from only two of the six organizations.

In all four ministries, respondents described changes made in their information dissemination activities since the Act. Several indicated a broadening of certain access: "[subjects] are informed to their right to have copies of data in their [file]"; "try to ensure that information requested is provided"; "offer more information without a formal request"). However, most respondents who had made changes in their dissemination practices indicated a tightening up on release of information. Comments ranged from "more cautious in giving information to other agencies" and "being more careful about what is said on phones to public" to "no information to be given out - to anyone". A number indicated an increased procedural formality in releasing information. Two people indicated that they will now respond only to written requests (thus creating a new formal channel of communication, replacing previous channels).

Comments which describe changes in record content may also signal changes in the channels of communication being used internally by employees. Such comments may be interpreted as signalling a change in channels from formal to informal channels or they may indicate that certain information is no longer flowing. Certainly some comments indicate a reduced volume of information storage in formal channels: "less information being retained", "eliminated extraneous material from working files", and "shredding documents".

The evidence of the questions on the survey instrument concerning information about the Act itself is interesting with respect to changes in direction of information flow. Although in some organizations, particularly the small crowns, there is a great reliance on outside sources of information about the Act, the Commissioner, whose mandate includes public education, ${ }^{25}$ is seldom cited. Moreover, although the organization Coordinators clearly represent a new channel of information in the organization, albeit a dedicated channel, the system of "liaison" contacts carefully established in four of the six organizations studied, are (on the evidence gathered from three of the four) not viewed by employees

\footnotetext{
24 In two of the eight organizations, the Coordinator and the head were one and the same individual and hence only one interview was conducted, combining elements from the protocols for both interviews.

25 See s.59(e) of the Act.
} 
as a reliable or preferred channel ranking ahead of either the new central authority of the Coordinator or the old familiar channel of the line superior. The request mechanism itself does not seem to be having much of an impact on the normal directions of flow of information to employees within the organization: only $3 \%$ of respondents had made personal information requests of their own organizations and even fewer, $2 \%$, had made such non-personal requests. Surprisingly, even this low level of use represented a higher level of use by employees for information about their own organizations than for information about other government institutions covered by this, or similar, legislation.

Most of the Coordinators and the heads interviewed demonstrated throughout the interviews a mind set about the statute which almost exclusively request driven. Their views on their organizations' abilities to cope are measured in terms of response times to requests and volume of requests. A typical observation was that the impact of the legislation on the ministry had been different from that anticipated in that the volume of personal data requests anticipated had not materialized but the use of the request mechanism for general information about policy initiatives in the Ministry had been far greater than expected. Only one ministry head seemed to gauge the success of the implementation efforts in terms other than ones related directly to the processing of requests, speaking of the potential for involvement of the requirements of the Act in all public contacts and creating systemic responses to policy areas which could create conflicts with the thrusts of this legislation. While this emphasis on requests may be entirely appropriate in terms of the provisions of the Act relating to information other than personally identifiable information, which deal with dissemination issues only and are themselves request driven, ${ }^{26}$ in the context of personally identifiable information, it tends to obscure the other requirements of the Act. Requests for personal information deal directly with issues of dissemination, as do requests for other information under the Act. However, requests for corrections or the appending of statements of disagreement are issues of information acquisition by the organization. The statute had provision affecting every stage of the information cycle with respect to information which is personally identifiable: acquisition, use, storage and retrieval, dissemination, and disposal. ${ }^{27}$ Since records can contain a blend of both personally-identifiable and non-personally identifiable information, ${ }^{28}$ all information operations in the organizations should be subjected to scrutiny as every stage in the cycle to ensure that the requirements of the Act with respect to

${ }^{26}$ See Part II of the Act. No other aspect of the information cycle with respect to information other than personally identifiable is dealt with in the statute. Acquisition, use, storage and retrieval, and disposal are left entirely to the discretion of the institution (as before the statute was passed). It may be prudent in the organization to make particular arrangements for storage and retrieval in order that the time limits imposed by the statute can be met, but this is entirely a matter for the organization, not a necessary mandate of the legislation.

27 See Part III of the Act.

${ }^{28}$ See s. $10(2)$ of the Act, which establishes the severability of records. 
personally identifiable information are being met in every case. This broader thrust was missing from the discussions with most of those interviewed.

Thus the evidence indicated that the first hypothesis, that changes in directions of information flow have occurred in the eight organizations as a result of this legislation, could not be supported.

The evidence with respect to the type of channels actually being affected by the legislation did not support the hypothesis that formal channels would be more affected, although the tenor of the conversations with the heads and Coordinators would have suggested an almost exclusive emphasis on formal channels. The evidence about changes in actual formal and informal channel use in the general information context in the organizations was derived largely from the indirect evidence of the changes in content reported by employee respondents to the survey. Although there was evidence that the content of written formal artifacts had been altered since the Act (generally by deleting personal opinions), that evidence did not support the hypothesis that these channels had been affected to a greater degree than the informal, and, indeed, there is some evidence in the comments to suggest that information is being switched from formal to informal channels in reaction to the perceived vulnerability of formal channels to access requests (information gathered orally not being transcribed or an informal written source of information being used to record information previously placed in formal sources). This tentative proposition is further supported by the observation that request driven changes are being made to a great extent in the area of record content and storage rather than in the directions of information flow. The evidence of the channels used in information flow about the Act itself would suggest that there seems to be more emphasis on formal channels, but that the employees would themselves prefer to de-emphasize the formal and increase the opportunities for informal channels to be used. Therefore, there was no support in the data for the hypothesis that formal channels of information flow have been affected more than informal channels. In fact, the evidence suggests that both types of channel were being affected: that employees are increasingly using informal channels. Formal channels were still continuing to be utilized by employees but the content of the artifacts used in them was being altered and reduced.

The finding that there was no evidence of consistent or widespread change in the directions of information flow in eight of the affected organizations casts serious doubt upon the effectiveness of this legislation in implementing changes in Ontario's information environment. The fact that there was no evidence that formal channels of communication had been affected to any greater extent than informal may cause policy-makers to enquire whether this legislation is indeed capable of accomplishing the policies declared in its opening section or whether it may be merely causing a shift in the type of channels being used for information transfer, rather than a shift in directions of information flow. 


\section{Launching the SnoopGuard ${ }^{\mathrm{TM}}$ PC Access-Control Product via a Microinvestment Strategy}

\author{
John C. Nash \\ Faculty of Administration \\ 136 Jean-Jacques Lussier Private \\ University of Ottawa \\ Ottawa, Ontario, K1N 6N5 \\ (613) 5645776 (messages) \\ (613) 5646518 (fax) \\ jcnash@acadvm1.uottawa.ca
}

\author{
Mary M. Nash \\ Nash Information Services Inc. \\ 1975 Bel Air Drive \\ Ottawa, Ontario, $\mathrm{K} 2 \mathrm{C}$ 0X1 \\ (613) 2250393 (voice) \\ (613) 2253781 (messages) \\ (613) 2256553 (fax)
}

\section{Abstract}

Products are developed and brought to market - launched - when entrepreneurs perceive that there is an opportunity to profit by so doing. Conventional wisdom considers that the launch of a new product requires a considerable investment. In this paper we discuss the motivations and development of a PC security product, trade name SnoopGuard ${ }^{\mathrm{TM}}$ for which the total cash investment has been limited to a very stringent ceiling. We believe such microinvestment strategies may be especially appropriate in recessionary times and especially for information-related products.

\section{Personal Computer Security Needs}

Because computers and the data they contain have become so central to much of the work done in our society, the costs of loss or damage (Nash and Nash, 1992) make it worthwhile protecting both systems and data. Loss and damage may be caused by:

Accidental erasure or over-writing of files;

Computer viruses or other vandalistic inventions;

Unauthorized access to information that should be kept confidential;

"Borrowing" of systems by colleagues, thereby disrupting our work;

Intrusion by those wishing to obtain private information or to vandalize data collections.

A variety of products and strategies may be used to counter these threats. Physical security of systems - traditional locks, keys, security officers, cameras, and so forth - are important for the stopping theft and physical damage to machinery and data media. Logical access controls in the form of passwords or biometric keys limit users to systems, data and resources that they are authorized to use. Encryption allows files or groups of files to be selectively protected.

Each approach to security has its strengths and costs. Encryption can provide high security, but loss of the logical key means that the information is lost also. Passwords may be left written on slips of paper, or easily guessed choices may be made. Locked doors everywhere are a hindrance to teamwork.

We chose to address the need for simple password access control to both PC systems and to their disks. There are some fairly simple software mechanisms that can provide such security by encrypting the control areas of the main fixed disk that allow the information on the disk - including the operating systems software - to be read. By providing a password, the user decodes the disk and can access information. Such mechanisms have three main failings: 